\title{
More inequality, but less coverage
}

\section{How and why TV news avoided 'The Great Debate' either side of the financial crisis 2008-14}

\author{
Richard Thomas
}

\subsection{The evolving landscape of inequality}

In the 1980s, British comedian Harry Enfield developed two characters whose profiles, intentionally or otherwise, highlighted increasing income inequality. With his reliance on benefits, alcoholism, violence and his dysfunctional family, 'Buggerallmoney' emphasized one extreme. Meanwhile self-made 'Loadsamoney' bragged about his 'wad' of cash, exemplifying an era of 'personal greed' (Butterick 2015: 80) and emphasized the other. Since then, income inequality has gained traction as a social issue, and is frequently viewed through the prism of the financial crisis 2008-14. The biggest crisis of capitalism 'since the crash of 1929' (Atkinson 2014: 472), however, contains conflicting narratives. While bank executives continued to enjoy high salaries, for example, the fall in real wages in the UK was much higher than that experienced by citizens in other nations (Machin 2015). Indeed, the economic crisis can be summarized as having a dramatic impact on citizens, while seemingly complicit financial sector actors did not suffer so obviously (Butterick 2015).

The bail-out of the Northern Rock Bank in mid-September 2007 is considered the first British manifestation of the unprecedented economic conditions that followed. In a report on $\mathrm{BBC}$ on 26 March 2007 about the multi-million pound pay award to Barclays CEO Bob Diamond, Robert Peston, who was an influential commentator business matters (Hulbert 2015), described income inequality as 'fast becoming one of the great debates of our age. The Conservative-dominated administration in power since 2010 had pursued policies closely associated with austerity, and yet between 2010 and 2015 the number of UK billionaires had doubled (Clarke-Billings 2015). The trend has continued in that while there were 134 billionaires based in the UK in 2017, 'fifteen years ago, there were 21' (Monaghan and Elgot 2017). Furthermore, top executive salaries have increased far faster than average pay and inflation (Topham 2013), income inequality in the UK being rated as 'well above the OECD average in the last three decades' (Organisation for Economic Co-operation and Development 2015: 1). 
In sum, the nation was by then 'the most economically unequal state within Europe' (Dorling 2016b).

Alongside the growing number of billionaires, increasing numbers of people in the UK became reliant on foodbanks and pay day loans to cover their basic daily needs (Poverty and Social Exclusion 2013). One month into the new Conservative administration in 2015, and amid plans for further cuts to welfare and public services, Julia Unwin of the Joseph Rowntree Foundation declared that 'thirteen million people in poverty is still too many in the world's seventh richest country' (Joseph Rowntree Foundation 2015). In 2018, the same organization reported that the figure had since risen to over 14 million (Joseph Rowntree Foundation 2018). With the UK simultaneously claiming both record numbers of billionaires and of citizens living in poverty, it is unsurprising that the causes and consequences of such disparity have gained wider recognition through seminal and accessible empirical works by Wilkinson and Pickett (2010), Piketty (2014), Dorling (2014), Sayer (2014) and others.

Even so, some with a pro-business world view have been unashamedly explicit about inequality and its potential justifications. In 2013 for example, then London Mayor Boris Johnson hailed greed as a 'valuable spur to economic activity' and called for the 'Gordon Gekkos of London' to display their avidity for economic growth (Watt 2013). Wealth, however, had become tarnished; executive salaries and perks were still considered unjustifiably high (Colvile 2014) and were often associated with greed and a lack of conscience. Most critical of all, Wilkinson and Pickett (2009: 502) suggested that 'inequality is highly predictive of health' and tangible links have long since been found between income inequality and life expectancy across a range of demographics (see inter alia Idrovo, Ruiz-Rodriguez and Manzano-Patino 2010, Torre and Myrskylä 2013).

However, the analysis of the news coverage of income inequality cannot simply polarize into the differential between wealth and poverty. The poorest and wealthiest in our societies for example are outnumbered by those who are neither rich nor poor but who during the financial crisis found their pay frozen, their savings reduced, their pensions delayed and their weekly shopping less affordable. Far from being a matter only for the wealthy or those professionally involved in it, business and financial news, in the words of SKY's TV Business and Economics editor Michael Wilson was happening 'in a town near you', and had 'marched right in through the front door, to you and your family' (Wilson 2008: 61). The wider focus of this research therefore is the coverage of poverty, wealth, the squeezed middle and income inequality (PWSIE issues).

There are sound reasons for examining the coverage of these issues on TV news in particular. First, information about poverty and income inequality generally emanates from the media (McCall 2013), and it not only provides a forum for debate but also shapes attitudes towards such issues (McKendrick et al. 2008). Furthermore, despite the exponential increase in internet use, more British adults use television as a news source than any other platform. Indeed, Ofcom (2018) reports that BBC and ITV are the two most used news sources in the UK. In sum, amid 'the proliferation of audiovisual devices', TV remains central within our cultural landscape (Lewis 2013a). As such, citizens might justifiably expect that such seismic financial changes are debated in useful and informative ways by a range of social actors within news reports adhering 
to noble journalistic principles. The core issue, therefore, is whether such expectations are met by the UK's two major TV news providers (BBC and ITV), and if not, why not? Since they are funded by a licence fee paid for by the public, it seems reasonable to expect that the $\mathrm{BBC}$, for example, should serve the people paying for its output by properly scrutinizing issues such as increasing inequality and others connected with it in appropriate detail. In sum, one might imagine that given the BBC's obligation to be impartial, it would provide high-quality journalism irrespective of the political and ideological dimensions associated with such contentious and polarized societal issues such as poverty and wealth.

British broadcasting's wider regulatory system applies to both BBC and ITV, among others, and dictates that a number of channels adhere to the ethos of public service. The benchmark against which any coverage of PWSIE issues should be considered is that the journalism they produce should act in the public interest. More specifically, normative models of economic, business and financial reporting expect it to reliably and impartially explain complex issues (Schifferes and Coulter 2013). One would expect this to be especially pertinent during the Global Financial Crisis 2008-14. By looking in specific detail at the year before the crisis began, and what is commonly recognized as the last year of the crisis, it will be possible to see not only what this coverage consisted of versus a normative model but also how it evolved.

\subsection{Quantifying the news, income inequality, poverty, wealth and the squeezed middle}

This research consisted of a content analysis to establish the locations and basic details about news items containing traces of PWSIE issues. Thereafter, a finer grained, textual analysis established embedded meanings within news reports. The 10.00 p.m. bulletins on weekday evenings on both the BBC and ITV were chosen on the basis that they both attracted the largest audience, were comparable in length (thirty minutes) and enjoyed the status as 'flagship' news broadcasts (Barnett and Gaber 2001). Only weekday bulletins were included in the sample, since weekend bulletins are considerably shorter, are often preoccupied with sport and generally offer less detail. The 2007 bulletins were accessed through a DVD archive at Cardiff School of Journalism, Media and Cultural Studies, ${ }^{11}$ while the 2014 bulletins were accessed through the Box of Broadcasts (BoB) database, an academic resource provided by the British University Film and Video Council (2018). In order to capture news data accurately, non-news elements such as idents, mid-bulletin summaries and warnings of forthcoming stories were not coded (Brunsdon and Morley 1978). Table 8.1 shows the details of the full research sample and the general data relating to the volume of all news within the chosen sample period.

News items containing any references to PWSIE factors were coded in detail. A news item is defined as a self-contained element within a wider story, and might include an edited package, a live interview, an anchor introduction and so on. References to income inequality, for example, are often nested in a wide range of stories (McCall 2005). There was no 'double coding' (Kalogeropoulos et al. 2015) in that items were 
Table 8.1 Summary of TV News (BBC and ITV) Wider Content Analysis

\begin{tabular}{lccccc}
\hline & \multicolumn{2}{c}{ BBC } & & \multicolumn{2}{c}{ ITV } \\
\cline { 2 - 3 } \cline { 5 - 6 } & $\mathbf{2 0 0 7}$ & $\mathbf{2 0 1 4}$ & & $\mathbf{2 0 0 7}$ & $\mathbf{2 0 1 4}$ \\
\hline Total bulletins logged & 212 & 245 & 171 & 244 \\
Percentage of all weeknight bulletins broadcast & 81.5 & 94.2 & 65.8 & 93.8 \\
Total number of news stories logged & 2,054 & 2,350 & & 1,882 & 3,048 \\
Average number of stories per bulletin & 9.7 & 9.6 & & 11.0 & 12.5 \\
Total news time in seconds & 300,483 & 370,304 & & 222,400 & 373,715 \\
Total news time in hours and minutes $($ to & $83 \mathrm{~h} 28 \mathrm{~m}$ & $102 \mathrm{~h} \mathrm{52m}$ & $61 \mathrm{~h} 47 \mathrm{~m}$ & $103 \mathrm{~h} 49 \mathrm{~m}$ \\
$\quad$ & & & & \\
\hline
\end{tabular}

deemed to concern wealth, poverty, the squeezed middle or income inequality, but not more than one of these. In other words, the most dominant issue was coded. While in practice this was quite straightforward, 'borderline' items were classified according to their main thrust: in practice these were often about a range of issues, and in such cases, a judgement was made about the central and most prominent element. Captured variables included the wider story subject containing the PWSIE element, and whether the element was the substantive within the news item, or just mentioned in passing. Intercoder analysis on a sample of data was carried out by a third party. ${ }^{22}$

Numbers, of course, only tell part of the story. Following the content analysis, selected news items containing a good example of a recurring theme were subjected to CDA in order to identify how these key issues were linguistically addressed. $\mathrm{CDA}$ is useful in that it accommodates meaning that is often implicit rather than explicit (Hansen and Machin 2013) while also revealing how power and ideology are propagated and preserved (Georgakopoulou and Goutsos 1997). As such, CDA seems eminently suitable for studying the reporting of issues such as poverty and inequality. Furthermore, CDA is an established analytical method within TV news (see Thomas 2016, 2019; Ekström 2001; Johnson et al. 2010; Joye 2010), since the 'reflective commentary' of broadcast news considers 'bias, (mis)representation, inaccuracy, distortion, ideology ... dumbing-down' and 'selective construction' (Montgomery 2007: 20). More critically here, CDA has emancipatory objectives (Mautner 2010) moving towards the call for intervention (Tenorio 2011). It is difficult to conceive, for example, how one might attempt to reveal potential injustice without accompanying such analysis with the wish to inspire some solutions. Essentially, the content analysis provided a 'blueprint' of typical modes of reporting PWSIE issues, and example reports fitting these blueprints and containing multiple characteristics were selected from the wider sample of 9,334 news stories.

\subsection{Shifts in coverage patterns $2007-14$}

Ahead of both content and critical discourse analyses, there were some prior assumptions that the quality of the news reporting might leave something to be desired. A priori, a case can be made that financial reporting falls short of its ideals amid concerns about 
the narrow backgrounds, outlooks and training of journalists themselves (see, inter alia, Fahy, O'Brien and Poti 2010; Merrill 2012). Furthermore, there are compelling arguments that the specialism promotes big business and the accumulation of wealth (McChesney 2003; Lewis 2013b) but that it has failed to anticipate notable financial scandals and crises (Doyle 2007; Tambini 2010).

Given that only 410 (4.3 per cent) of the total 9,334 news stories that were logged contained identifiable traces of PWSIE issues, it seems reasonable to think that these issues were not a major preoccupation for BBC and ITV news. There were reasonably encouraging signs however, in that across both bulletins in both years, between 79.5 per cent and 83.6 per cent of those stories carrying PWSIE issues did so within reporter packages. While 'live' news - reporters in the field or in the studio giving their reports or speaking live to a news anchor - is more interpretive and assists in providing up-todate or breaking news (Cushion and Thomas 2013), logically, reporter packages are more likely to supply background and context. In sum, therefore, serious, balanced discussions about key issues in focus are most likely to occur during the longer, more considered and generally factual reporter packages and it is here, without the breathless urgency of live coverage, that these issues are most likely to be reported in cerebral, purposeful ways.

Table 8.2 demonstrates, first, that PWSIE issues were generally more prominent on the BBC than on ITV, suggesting that in the first instance, the corporation's more demanding public service obligations are actually meaningful in this context. It is also clear that PWSIE issues were found in what are commonly recognized as hard news categories such as Politics and Foreign Affairs. In sum, it seems reasonable to infer that the core issues in focus here were located within the stories and conventions most likely to provide the greatest potential opportunities for serious discussion.

By 2014, PWSIE stories were more likely to be found in stories about the economy, business and finance. One typical example included a story on BBC on 26 January 2014 which speculated that if the Conservatives won the general election 2015, there would be more spending cuts which would more likely disadvantage those with lower incomes; another BBC story on 23 January 2014 covered Prime Minister David Cameron's claims that the economic recovery would benefit everyone and that wages would recover. As another example, a story on ITV the previous day described how a tiny property for sale for a comparatively large sum in London accentuated the lack of affordable housing in the capital.

Notably, apart from the issue of wealth, all PWSIE issues were usually reported thematically, meaning that the issue was covered in general terms, without relying on an example or personal story to define it. The squeezed middle and income inequality in particular were both presented almost entirely thematically. One interpretation of this is that TV news misses the opportunity to increase its impact since focusing on those with personal experience of poverty (in other words, episodically), for example, is often an effective means of engaging wider audiences (Robinson et al. 2009). However, thematic framings describe more general elements such as quantification, geographical differences, statistics and wider explanations. Accordingly, this can be seen as a positive sign, since episodic framings - which concentrate on particular personal stories and narratives are thought to simplify issues to the level of 'anecdote' (Lyengar 1990), meaning that 
Table 8.2 Types of News Story Associated with Poverty, Wealth, the Squeezed Middle and Income Inequality (PWSIE) Themes

\begin{tabular}{|c|c|c|c|c|}
\hline & \multicolumn{2}{|c|}{ BBC } & \multicolumn{2}{|c|}{ ITV } \\
\hline & 2007 & 2014 & 2007 & 2014 \\
\hline Total number of stories & 2,054 & 2,350 & 1,882 & 3,048 \\
\hline $\begin{array}{l}\text { Total number of stories containing } \\
\text { wealth, poverty, income } \\
\text { inequality and squeezed middle } \\
\text { stories }\end{array}$ & 110 & 133 & 50 & 117 \\
\hline $\begin{array}{l}\text { Relative number of all stories } \\
\text { containing wealth, poverty, } \\
\text { income inequality and squeezed } \\
\text { middle stories }(\%)\end{array}$ & 5.3 & 5.7 & 2.7 & 3.8 \\
\hline Types of News Story & $\begin{array}{l}\text { Percentage } \\
\text { of Stories }\end{array}$ & $\begin{array}{l}\text { Percentage } \\
\text { of Stories }\end{array}$ & $\begin{array}{l}\text { Percentage } \\
\text { of Stories }\end{array}$ & $\begin{array}{l}\text { Percentage } \\
\text { of Stories }\end{array}$ \\
\hline Economy, Business & 23.6 & 20.0 & 48.1 & 45.2 \\
\hline Foreign Affairs & 29.0 & 38.0 & 12.0 & 12.0 \\
\hline $\begin{array}{l}\text { Politics (inc. process, policy, scandal, } \\
\text { people) }\end{array}$ & 10.0 & 4.0 & 14.3 & 12.0 \\
\hline Sport & 3.6 & 6.0 & 7.5 & 6.0 \\
\hline War / Conflict / Terror & 4.6 & 4.0 & 6.8 & 5.1 \\
\hline Immigration & 6.4 & 2.0 & - & 4.3 \\
\hline Crime & 3.6 & 8.0 & - & - \\
\hline Home Affairs & 9.1 & - & - & - \\
\hline Health/Medical/Disease/Research & - & - & 0.8 & 4.3 \\
\hline Others (all very small numbers) & 10.1 & 16.0 & 10.5 & 11.0 \\
\hline Total & $\approx 100.0$ & $\approx 100.0$ & $\approx 100.0$ & $\approx 100.0$ \\
\hline
\end{tabular}

understandings of such issues are 'disorganized, and isolated' (De Vreese 2003: 38). So, at first glance, by virtue of their general embeddedness within longer, reporter packages about hard news stories and thematic framing, it seems as though there are some important prerequisites in place for PWSIE items to be reported both seriously and in depth.

However, such high hopes do not last long. Indeed, as Table 8.3 shows, the numbers of items involving what might be considered as the most acute issues involving the greatest levels of suffering - poverty and income inequality - actually decreased over the period defining the financial crisis. Stories about wealth and the squeezed middle increased, most likely explained by an emphasis on unusually remuneration and reward, and the fact that the financial crisis - by way of its impact on wages, prices, mortgages, public spending and pensions - was of general concern to those who considered themselves neither wealthy nor poor. This is despite a reasonable expectation that such issues might attract considerably more media scrutiny after a financial crisis lasting several years. It is possible, of course, that those determining news agendas might have felt that the public might have been grown tired, for example, of stories about banks, but such 'bad news' stories continued throughout 2014 (Thomas 2019).

Even more inexplicably, within those stories where PWSIE issues were present, the issues were actually less prominent. In other words, these issues were less pivotal 
Table 8.3 Change in Number of Poverty, Wealth, the Squeezed Middle and Income Inequality (PWSIE) News Items 2007-14

\begin{tabular}{|c|c|c|c|c|c|}
\hline & \multicolumn{2}{|c|}{2007} & \multicolumn{2}{|c|}{2014} & \multirow[b]{2}{*}{ Change } \\
\hline & BBC & ITV & BBC & ITV & \\
\hline Total items containing POVERTY & 51 & 16 & 30 & 31 & -6 \\
\hline Total stories & 2,054 & 1,882 & 2,350 & 3,048 & \\
\hline $\begin{array}{l}\text { Percentage of stories containing } \\
\text { POVERTY }\end{array}$ & 2.5 & 0.9 & 1.3 & 1.0 & -1.1 \\
\hline Total items containing WEALTH & 23 & 18 & 35 & 31 & 25 \\
\hline Total stories & 2,054 & 1,882 & 2,350 & 3,048 & \\
\hline $\begin{array}{l}\text { Percentage of stories containing } \\
\text { WEALTH }\end{array}$ & 1.1 & 1.0 & 1.5 & 1.0 & 0.4 \\
\hline $\begin{array}{l}\text { Total items containing SQUEEZED } \\
\text { MIDDLE }\end{array}$ & 14 & 4 & 49 & 46 & 77 \\
\hline Total stories & 2,054 & 1,882 & 2,350 & 3,048 & \\
\hline $\begin{array}{l}\text { Percentage of stories containing } \\
\text { SQUEEZED MIDDLE }\end{array}$ & 0.7 & 0.2 & 2.1 & 1.5 & 2.7 \\
\hline $\begin{array}{l}\text { Total items containing INCOME } \\
\text { INEQUALITY }\end{array}$ & 22 & 12 & 19 & 9 & -6 \\
\hline Total stories & 2,054 & 1,882 & 2,350 & 3,048 & \\
\hline $\begin{array}{l}\text { Percentage of stories containing } \\
\text { INCOME INEQUALITY }\end{array}$ & 1.1 & 0.6 & 0.8 & 0.3 & -0.6 \\
\hline
\end{tabular}

within the stories that carried them. Figure 8.1 shows the percentage of items where PWSIE elements were a substantive issue within the item carrying them. It is clear that across both TV news channels, such issues were less central to the news reports in 2014 than they were in 2007.

Taken together, these are worrying findings for those who feel that as the most consumed news platform, TV news should be at the forefront of reporting such social issues, especially given that the global financial crisis accentuated their impact. The inevitable conclusion is that across years and channels, despite proper discussions about these important social issues having been given every opportunity to develop, PWSIE issues were less evident and less prominent within news agendas in 2014 than they were in 2007. While there is no data showing what happened between these years, given the severe global financial disturbance that occurred between them, it seems reasonable to imagine that PWSIE issues might have become more prominent within news agendas by the time comparative normality returned. As it was the news focus seemed to be elsewhere, and these human conditions look to be increasingly marginalized.

\subsection{Discourses of suffering, corpulence and inequality}

While content analysis determines the components of a news text, qualitative analysis 'rehumanizes' statistical findings (Gephart 2004: 455). In isolation, descriptive 


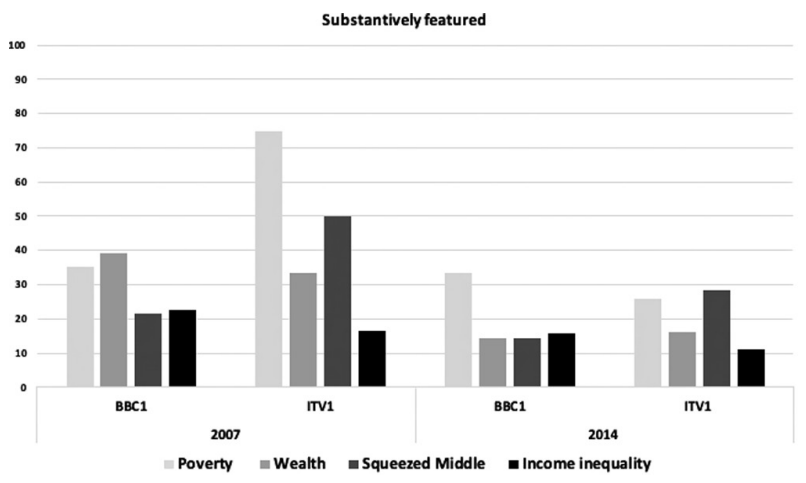

Figure 8.1 Prominence of poverty, wealth, the squeezed middle and income inequality (PWSIE) issues in the news.

statistics may be unsatisfactory (Ackroyd and Karlsson 2014) since they often ignore, for example, the language used in news reporting. Scrutiny of the particular discursive presentations of these issues via commentaries, sound bites and interviews provides a much fuller picture.

In the case of poverty, the decrease in coverage is harder to understand, since stories about international poverty in 2007 - mainly focusing on Zimbabwe's economic implosion - had, by 2014, given way to a more UK-based news focus. Hare (2014) notes that news can often be conceptualized like a hurricane, since the nearer you are to it, the more notice you take of it; it seems reasonable to imagine therefore that, as poverty came closer to home, this fact alone might have generated more stories than before. In reality, though, 106 more bulletins and over 60 hours of extra news in the 2014 sample versus the 2007 sample actually produced less coverage of poverty rather than more.

In 2014, the poverty spotlight fell on reports about increasing poverty levels, how people are increasingly reliant on food banks, how church leaders took to criticizing the prevailing welfare system and so on. ITV's bulletin on 16 April 2014, for example, describes how an unemployed young father had become reliant on foodbanks to feed his family. The man - Steven Jones - starkly defined his financial situation as a bleak daily choice where 'either the kids go without, or I go without, and I'd rather the kids have food before I have anything to eat'.

When, albeit less often than in 2007, the news focus became more international, the ITV example in Figure 8.2 underlines the diminishing prominence of poverty within such news reports. As was made clear by anchor Mark Austin's introduction, the thrust of the story about the deteriorating conditions within a refugee camp in the Lebanon was not the plight of those forced to live there but concentrated instead on the experience of actress Sienna Miller when she visited. The story (made up of a very brief anchor introduction and an edited package) both begins and ends with details of Sienna Miller's 'narrow escape.' Closer analysis of the language used, however, suggests that this might not have been as close as suggested.

Correspondent Nina Nannar refers to an explosion at the checkpoint that they 'had come through that morning. This actually appears considerably less close than the 

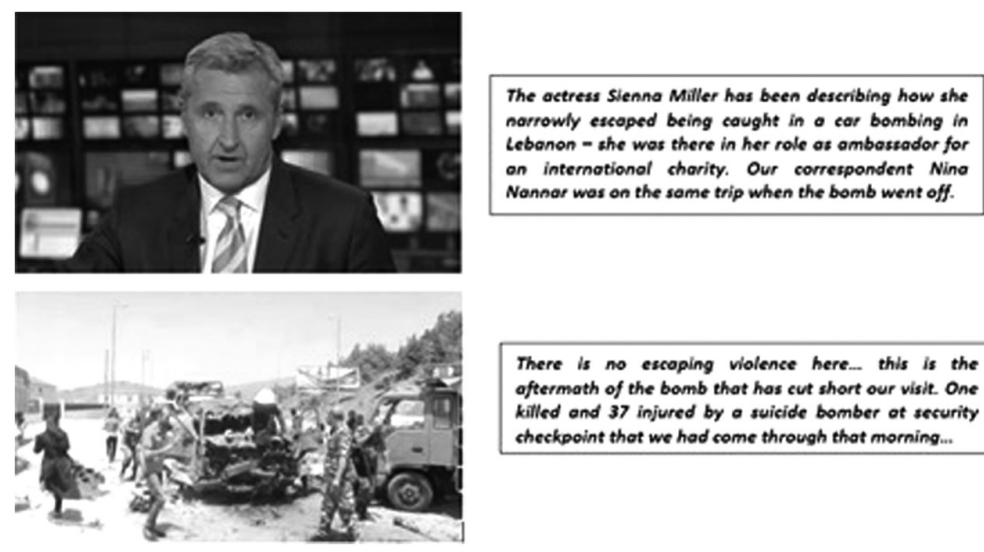

Figure 8.2 ITV's report about Sienna Miller's trip on 23 June 2014.

'narrow escape' indicated by Mark Austin. The report concludes with another reminder of the apparent danger to Sienna Miller, and her appearance resonates with notions that while celebrities attract media attention, overly theatrical coverage detracts from the more serious reporting of poverty (Lugo-Ocando 2014). Poverty and the inhuman living conditions in the camp seem to play second fiddle to Sienna Miller's 'escape'. This appears a typical example of how a PWSIE issue - poverty - is often relegated to a more marginal role within a news item.

Another ITV story focused on the other extreme of the wealth continuum versus those suffering in the Lebanon. Since the so-called 'Shareholder Spring' in 2012 (see Thomas 2016), a number of news stories focused on the high pay awards to a range of corporate and sporting figures. While this is not surprising, it is notable that the moral/ ethical element of high pay was often marginalized in favour of a fascination about the personal opportunities for acquisition enabled by such wealth. Take for example ITV's report on 1 September 2014 shown in Figure 8.3, which explained that football club Manchester United had just signed the Colombian striker, Falcao.

The report features anchor Mark Austin and sports correspondent Ian Payne, and like many other stories about wealth, is typically episodic and focuses on the large sums involved and what spending opportunities such wealth provides. Payne's lexical choice of 'wages' implicitly encourages viewers to compare the sum to their own 'wages' and is somehow incongruous, since 'wages' suggests a more blue-collar level of reward. Despite the general tone of incredulity expressed by both journalists, neither questions the system allowing such large sums. Payne's perceived 'big question' indeed is not how such salaries are justified against the prevailing socio-economic backdrop where inequality was growing, but instead concerns how such amounts might be spent. Of course, this might have been a light-hearted and rhetorical way to conclude the item, but even so, it was the only 'big question' that was posed. Others including 'how can such salaries be justified?' were absent. Viewers are invited to consider how they might spend $£ 346,000$ per week, even though many of those watching would likely be more concerned about covering their essential monthly costs. In simple terms, 


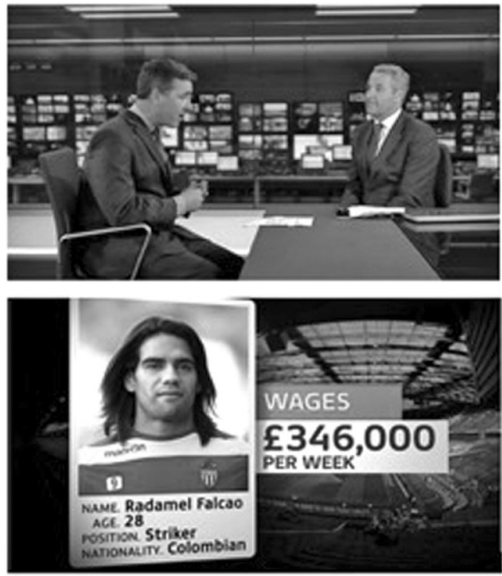

Here's the kicker - they will have to pay his wages which ore the highest in premier league history at f346,000 per week, and that brings the total cost to $f 24$ million...the big question remoins - how do

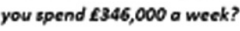

Figure 8.3 ITV's report that Manchester United have signed Falcao on 1 September 2014.

the emphasis of the report does not move beyond an almost light-hearted discussion about consumerism and acquisition, similar to the way that the good fortune of lottery winners is often reported. In these cases, too, there is a regular emphasis on 'the first thing' that the winner will buy with their new found wealth.

However, the emphasis on consumerism predated the financial crisis beginning in 2008. There was another pertinent example in 2007 when both channels reported the trial and subsequent imprisonment of Conrad Black, the ennobled former newspaper owner who was accused of defrauding his shareholders. Both channels featured interviews with journalist Andrew Neil, described as someone that knew Black well. In the ITV report of Black being found guilty on 13 July 2007 (Figure 8.4), anchor James Mates continued the preoccupation with the spending power of wealth by asking Neil whether Black's parties were 'as extravagant as made out in court'. Neil answered accordingly that this seemed to be the case. When on 10 December 2007, the BBC reported the sentencing of Conrad Black to 6 and a half years' imprisonment (also Figure 8.4) it too called upon the testimony of Andrew Neil, who responded with a similar assessment. Both reports typify the dominant episodic framings evident within wealth coverage across years and channels, with the narratives strongly focusing on lifestyle details and referring to examples such as the ' $\$ 6,000$ toilet seat', the ' $\$ 2,000$ handbag,' 'toys', 'private jets' and 'parties' attended by royalty.

Perhaps even more significantly however, was Andrew Neil's consistent focus on 'the rules' within both his contributions, several months apart, on different channels. He suggests that Conrad Black was not being punished for his lifestyle, but for how his wealth had been acquired. The inference is that although such illegal behaviour is unacceptable, the way capitalism incentivizes such behaviour is legitimate, so long as the 'rules' are observed. Neil presupposes that the 'rules' themselves are legitimate, and the point is not challenged within either interview. The idea that it might be the 'rules' themselves that might be insufficiently robust to prevent the potentially unethical and unpopular acquisition of wealth - as was alleged about numerous bankers during the 

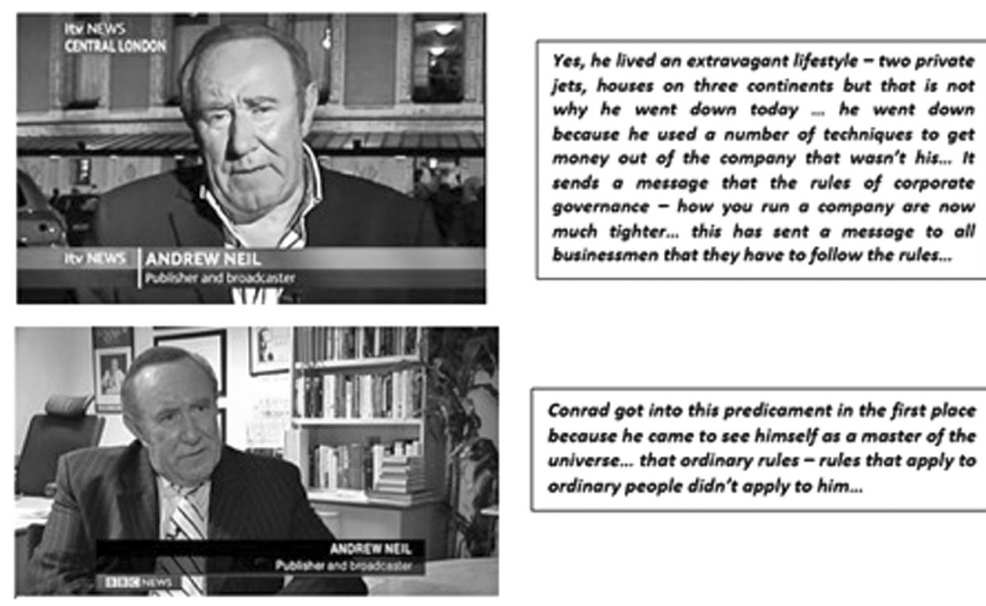

Conrad got into this predicament in the first place becouse he came to see himself as a master of the universe... that ordinary rules - rules that apply to ordinery people didn't apply to him...

Figure 8.4 Andrew Neil's comments about Conrad Black on ITV in 13 July 2007 and BBC on 10 December 2007.

crisis - is not mentioned. Ironically, however, 'rules' might be entirely the wrong word in this case, since it seems clear that the system that allows record levels of wealth and poverty to coexist is actually characterized by systemic deregulation.

\subsection{Neoliberalism: The fewer 'rules' the better}

In 2014, towards the end of the crisis when the news more widely revealed narratives of mismanagement, greed, excess and criminality, both BBC and ITV seemed intent on regularly defending a neoliberal approach. Figure 8.5 shows various prominent interjections on both channels that provide a robust defence of free markets. The first example comes from the BBC on 30 July 2014 and a report about how bank bonuses might be repaid by those found to have acted unethically. Within the report, Anthony Browne from the British Bankers Association suggests that when compared with bankers in other financial centres, London bankers are the most regulated and lowest paid. He articulates this as a tangible threat to jobs and taxation revenue. Of course, his views are understandable given his role with an association supporting the British banking sector, but the point is that though this contributor was given the chance to build a defence, those with contrasting opinions were not.

In the next example, from ITV on 16 January 2014, employer Leanne Hewitt claims that an increase in the minimum wage - often seen as a Keynesian intervention that disturbs free market economics - will ultimately mean that some of her employees would lose their jobs. The inference is that being able to offer the lowest price in a competitive market takes precedence over a fractional increase in the minimum wage. In the final example, a BBC story about rent capping on 1 May 2014 was punctuated by a soundbite from Andrew Wernick, described simply as a 'Landlord'. His impassioned 
defence of the free market suggests that this is the 'nanny state' exerting its influence and that suppressing 'free enterprise' is a folly. Of course, these are not journalists talking, but these interjections have been selected as part of an edited package, and as such can be thought of as the work of journalists and editors.

On other occasions, it is the journalist that actually constructed a similar argument. For example, in a story on BBC on 3 February 2014 describing how Lloyds Bank had improved its performance, anchor Huw Edwards begins by explaining that Lloyds Banking Group was selling $£ 5$ billion worth of shares, but that the share price had fallen after the announcement that $£ 1.8$ billion was being allocated to settle claims arising from the mis-selling of payment protection insurance (PPI). Thereafter, Robert Peston's report suggested that the PPI refunds actually represented a 'massive silver lining', in that the money being given back to consumers would contribute significantly to the country's growing economy. By any measure, this seems to be a very positive spin on what many would consider a financial scandal, fuelled by an insufficiently rigorous regime of financial regulation.

But perhaps this is not the most explicit example of a journalist defending a neoliberal economic system where regulations are perceived as restrictive. As per Anthony Browne's argument (Figure 8.5), a key defence is that unfettered wealth creates jobs for others and generates significant tax revenue. In 2007 - before income inequality became an even more serious issue - a BBC report introduced by anchor Fiona Bruce on 20 June 2007 focused on the suggestion that 'billion-pound private
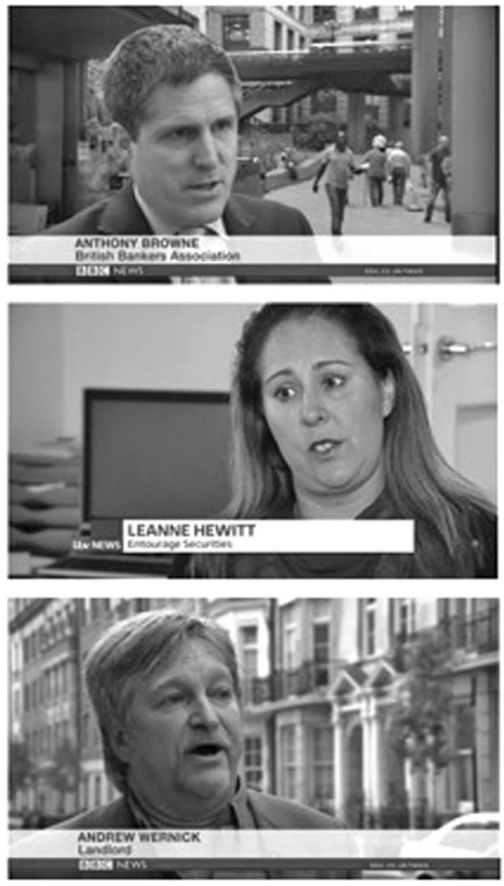

Figure 8.5 Various defending of free markets.
We now hove the toughest regime in banking pay of any global financiol centre - bankers are octually paid less here than they are in New York, Singapare and Hong Kong, and wltimately, this could have an impoct on the competitivenest of london as a financial centre and the jobs and tax poid here.

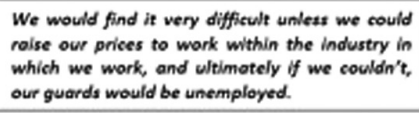

We would find it very difficult unless we could roise our prices to wark within the industry in which we work, and ultimotely if we cocildn't, our guards would be unemployed. 

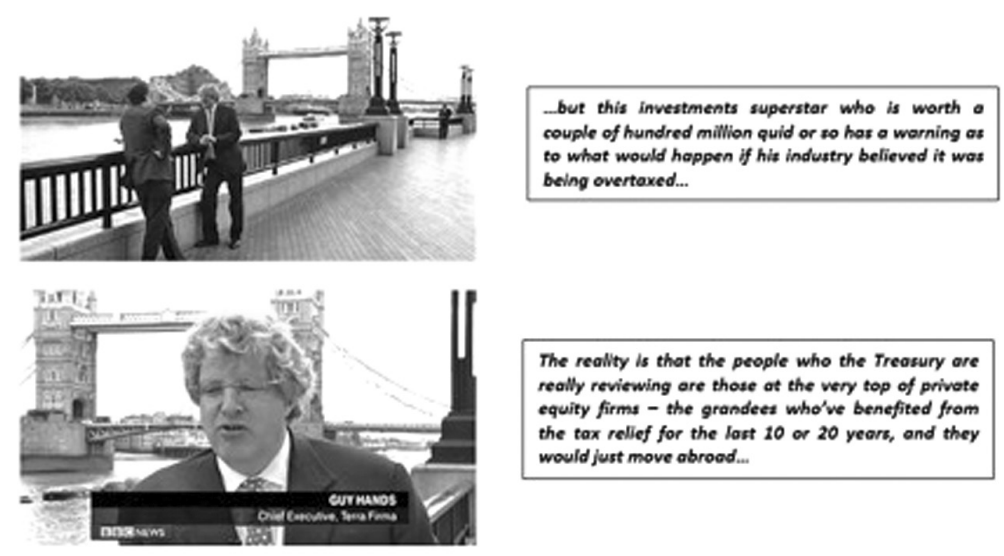

The really is that the people who the Treasury are really reviewing ore those ot the very top of privote equity firms - the grandees who've benefited from the tax relief for the last 10 or 20 yeark, and they would just move abrood...

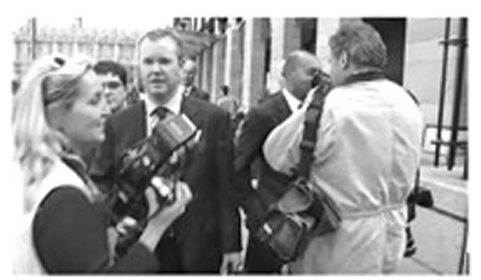

If the privote equity starz deport these shores, there'd be a cost to Britain, so imposing fair taxes won't be cosy...

Figure 8.6 The 'cost' of increasing the taxation system to Britain on the $\mathrm{BBC}$ on 20 June 2007.

equity deals' were being criticized for the low rate of tax they are subject to. Concluding the report (Figure 8.6), Robert Peston interviews 'investments superstar' Guy Hands who warns that if the UK taxation regime changed, then these business leaders - and presumably the businesses that they run and jobs that they provide - would move overseas. Perhaps most compelling of all is Peston's final comment. He repeats this alert by once again warning about the 'cost' to Britain; however, he dodges the ethical and moral dimensions of the issue that he himself earlier in the report had defined as equity bosses actually paying 'lower rates of tax than their cleaners'. Notwithstanding that the taxes being referred to are different - income tax for the cleaners and capital gains for the equity bosses - the inequality of their respective situations is clear.

This stout defence, however, is not confined to the BBC. On 15 January 2014, ITV Business editor Laura Kuenssberg concluded her interview with anchor Mark Austin with a similar warning as that voiced by Peston, in that 'we have to be careful how far we go ...' when it comes to regulating the banking sector with any restricting of bonus payments. In both these examples, viewers are left with the final (and therefore perhaps, also the most memorable) message that the financial sector should be protected and not further regulated. This message, of course, is supportive of those who have earned millions in bonuses, and in turn this further drives inequality. Such qualitative examples can be added to the fact that in this large sample, there was less PWSIE news after the financial crisis than before and that such issues were less prominent. In 2007, as we have heard, Robert Peston suggested that income inequality was 'the great debate'; if 
indeed it was - and the compelling evidence suggests that it should have been - then the unavoidable conclusion is that it was not being debated on TV news.

\subsection{But why is inequality not being discussed?}

On a superficial level at least, the UK's TV news landscape - as represented here by $\mathrm{BBC}$ and ITV - apparently provides the right conditions for reporting serious news and topics associated with social justice. Such issues are generally covered within longer news conventions providing opportunities for more detailed reporting. However, there was generally less coverage of poverty and inequality, and PWSIE issues were featured less prominently. Moreover, both ITV and BBC seemed reluctant to interrogate the financial system seemingly enabling increasing income inequality. Even more damning, the defence of neoliberalism economics and the promotion of systematic deregulation are so explicit that it hardly requires the sharp incisive potential of CDA at all. The evidence here supports Grisold and Theine's (2017: 4278) analysis of the coverage of inequality in that there seems a lack of diversity of information on economic inequality' and 'a neglect of the positive implications of redistributional policies to diminish inequality'.

One explanation for the lack of news about income inequality is that it is simply not newsworthy enough, that it may have lacked some key news values - those characteristics in a news story such as negativity, unexpectedness and so on that editors anticipate the audience will be drawn to - and that as a story by itself, income inequality may be too complex to understand (McCall 2013). Kitzinger (1999), for example, proposes that media portray 'risk' irresponsibly, preferring sensational impacts over cumulative outcomes, with events taking precedence over backgrounds. Indeed, the complex, gradual nature of income inequality may be less newsworthy than other stories because it is a 'slow burn' issue. According to the 'burglar alarm' model (Zaller 2003), for example, extraordinary events such as catastrophes, trials and misdemeanours are needed to promote stories onto news agendas. As such, income inequality might be considered similar to climate change; both might actually be getting worse but at the same time are both background issues that rarely make the news. News channels are unlikely to simply report that 'the environment is still being damaged' or 'there is still great inequality'; it might take a research project or a statement by someone famous to generate sufficient news value for it to feature within a news programme containing on average between 9.7 and 12.5 stories per bulletins (see Table 8.1).

This, however, does not explain why income inequality would be less newsworthy after the financial crisis, especially since the likes of Wilkinson and Pickett (2010), Piketty (2014), Dorling (2014) and others had made the issue much more prominent than before, reaching wider audiences with information about its potential dangers. The answer, perhaps, goes beyond on-the-hoof editorial decisions made in busy newsrooms, and concerns the wider grip of, and deep reliance on, capitalism.

Empirical evidence indicates quite clearly that across mainstream media platforms, the maintenance of capitalism through economic growth is presented as unequivocally 
positive (Lewis and Thomas 2015; Thomas 2018). Logically, increased output of goods and services (growth) is driven by continuing demand. Irrespective of any environmental concerns (Lewis and Thomas 2015), relentless consumption is therefore fuelled by advertising. Capitalism therefore can be considered to hold modern democracies in a vice-like grip, and based on the quantitative and qualitative evidence here, TV news does not offer any critiques or alternatives. Put more succinctly, it is hard to contest the conclusion offered by Kay and Salter (2014) that at a point when free market economics should be justifiably held to account by public service media, they fail to do so, and instead, it continues to promote what appears to be a flawed model serving the few and not the many.

The idea that the pro-business media organizations generally shy away from discussing income inequality is supported by some simple analysis comparing the Telegraph (a UK broadsheet allied to the political right and whose owners have extensive business interests) to the Guardian which has a liberal-minded ethos and an ownership model that does not benefit 'a proprietor or shareholders' ('The Scott Trust: Values and History', 2015).

Generated with the help of the Nexis UK database, Figure 8.7 shows how often the phrase 'income inequality' was used in all print editions (including Sunday editions) of these newspapers between 2007 and 2018. Even without the notable spike in 2016, The Guardian consistently features the phrase far more than the Telegraph. Indeed, for the Telegraph, the 'great debate' only merited 157 mentions in 11 years. In short, where there is a need to generate value for owners and shareholders, capitalism and commercialism are the dominant codes, and income inequality is marginalized. This particular comparison is pertinent to the discussion when the TV news data herein is not considered holistically, and the channels are looked at more as separate entities.

Of course, there are some similarities between BBC and ITV. Not least, there is some travel back and forth involving key journalist staff; indeed since this research was

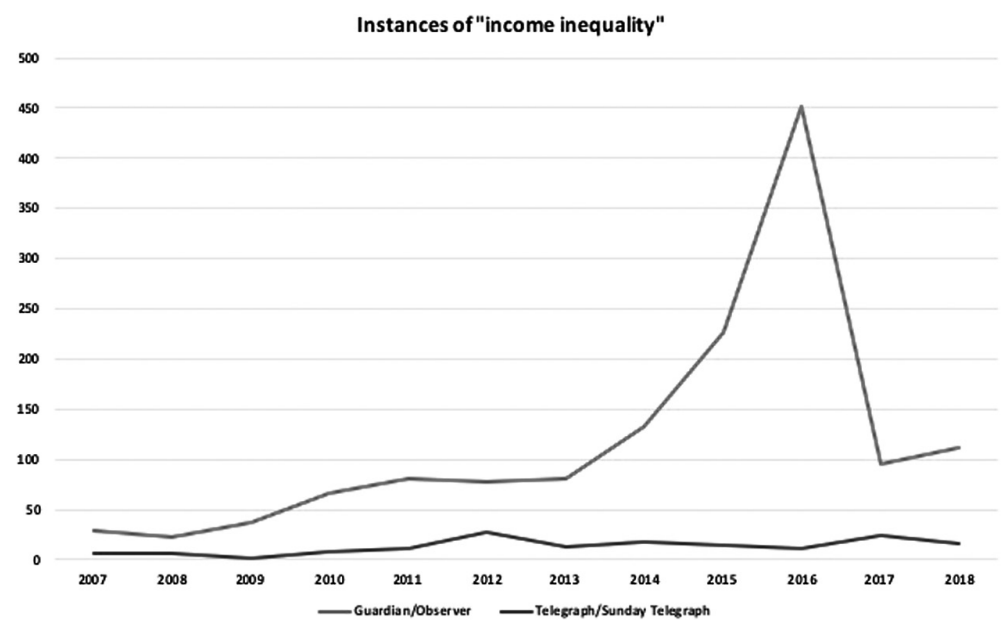

Figure 8.7 'Income inequality' in the Telegraph and the Guardian. 
conducted, both Robert Peston and Laura Kuenssberg moved from one channel to the other. In 2015, Peston became political editor of ITV News, and Keunssberg took over the same role at the BBC. But there are some fundamental differences in terms of what might be expected from each. For example, with its primary position as the nation's public service broadcaster, one might reasonably expect that the $\mathrm{BBC}$ would put the interests of its wider viewership first, especially since it is funded by a licence fee. ITV, on the other hand, has lighter public service obligations, and relies on capitalism manifested as advertising - to pay for its broadcast content.

For different reasons, both channels might be fundamentally unsuited to the reporting of income inequality, and the reasons involve mechanisms embracing themes of power, politics, governance, public service, funding and tradition. ITV's general support of a neoliberal system might be more simply explained in that since it wishes to attract advertisers it is unlikely to undermine the economic system enabling such potential investors to thrive. However, the BBC's apparent unwillingness to challenge capitalism seems more difficult to explain. There are historical suggestions that the BBC's business reporting traditionally avoids questioning the financial status quo, instead preferring a more superficial focus (see, inter alia, Svennevig 2007; Lewis 2013b; Jones 2014). Given its public-serving objective, the $\mathrm{BBC}$ might even be considered to be in breach of such noble objectives, especially in face of 'the incessant prodding of commercial interests, combined with the Thatcherite love of the market' (McChesney 2000: 249).

More widely, there are suggestions that business journalism might be beset with bias and vested interests (Shaw 2015). More specifically, some notable empirical studies (inter alia Wahl-Jorgensen et al. 2013; Cushion, Lewis and Callaghan 2017; Lewis and Cushion 2019) support a general thesis that politically the BBC has moved to the right. While still employed by the BBC, for example, Robert Peston conceded that 'the broadcaster actually veers towards a right-wing, pro-establishment view for fear of criticism' (Sommers 2014).

The persuasive argument is that $\mathrm{BBC}$ output reflects the preferences of those who run it and produce its content. According to Freedman (2019: 209), 'Senior editorial appointments also reflect an underlying commitment to an aggressive defence of the status quo'; many key correspondents, he suggests, are 'establishment insiders'. Both Jones (2014) and Freedman (2019) provide detailed and compelling examinations of $\mathrm{BBC}$ hierarchy from Chairmen to editors, producers and senior journalists, and both conclude therein a widespread and indisputable support for conservative ideology and free market ideals. Robert Peston, who was a key onscreen figure in both 2007 and 2014 research samples, describes the BBC as preoccupied with not breaking accepted rules and conventions when training its journalists (Higgins 2015). Freedman (2019) also points to key figures oscillating between the BBC and organizations that would naturally support free markets, the potential collusion between the $\mathrm{BBC}$ and the government when deciding the licence fee, and finally, an assertion that the corporation's key positions are held by members of the most elite strata of British society.

The suggestion is that 'while the $\mathrm{BBC}$ claims scrupulously to adhere to its obligation to respect due impartiality', its journalism 'deliberately bows down to a prevailing neoliberal consensus' (Freedman 2019: 211). Such a notion has considerable support (see Kay and Slater 2014; Kelsey et al. 2016) and is difficult to resist. 


\subsection{Where now?}

This all leads to some inevitable questions. First, will the 'big debate' on TV news ever address the serious elements of wealth, poverty and inequality? Second, if we cannot rely on our public service broadcasting system to report income inequality - a critical issue relating to our collective well-being and allegedly 'the big debate' - then who can we rely on?

And yet, there is still hope. Irrespective of the evidence here, both ITV and the $\mathrm{BBC}$ are capable of meeting its obligations to responsibly report such issues. Emerging from this wider research were examples of ITV demonstrating that they were more than capable of holding a major bank to account with critical and probing journalism. ITV journalists relentlessly reported the problems experienced by Barclays PLC even though the very bulletins containing the censorious reporting were punctuated by advertisement breaks actually featuring commercials for the very same organization (see Thomas 2019). Similarly, even though it was the only story to address income inequality in terms of its causes, consequences and cures within over 9,000 news stories and 350 hours of news, on 28 January 2014, the BBC featured a story about how governor of the Bank of England Mark Carney gave a speech that was highly critical of city greed and rising inequality. In concluding a wide-ranging report suggesting that progressive taxation might solve the problem, Business editor Kamal Ahmed concluded with the words 'if capitalism is to flourish, it is time for reform. One suspects that before income inequality can become a less serious problem, such reform is required to extend beyond the prevailing economic system of neoliberalism and must reach the practices of the UK's broadcasting system.

\section{Notes}

1 This was a DVD archive at Cardiff School of Journalism, Media and Cultural Studies containing a library of DVD recordings that had been made by the technical team at this department. The archive comprised of DVD recordings of each day's key news programmes throughout the year. A quantity of 2007 bulletins were missing from the archive, but I believe a total of 171 still represents a large percentage of what was broadcast.

2 Of the Krippendorf Alpha scores calculated for the intercoder phase of study, variables exceeded 0.77 , meaning that all were 'substantial' with many rated as 'almost perfect' (Landis and Koch 1977: 165). 
